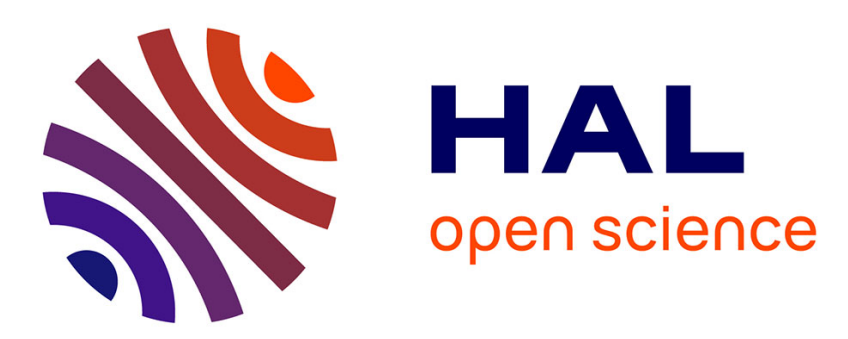

\title{
Polymerization of Cyclic Carbamates: A Practical Route to Aliphatic Polyurethanes
}

Dapeng Zhang, Yang Zhang, Yujiao Fan, Marie-Noelle Rager, Vincent Guérineau, Laurent Bouteiller, Min-Hui Li, Christophe Thomas

\section{To cite this version:}

Dapeng Zhang, Yang Zhang, Yujiao Fan, Marie-Noelle Rager, Vincent Guérineau, et al.. Polymerization of Cyclic Carbamates: A Practical Route to Aliphatic Polyurethanes. Macromolecules, 2019, 52 (7), pp.2719-2724. 10.1021/acs.macromol.9b00436 . hal-02357495

\section{HAL Id: hal-02357495 https://hal.science/hal-02357495}

Submitted on 18 Sep 2020

HAL is a multi-disciplinary open access archive for the deposit and dissemination of scientific research documents, whether they are published or not. The documents may come from teaching and research institutions in France or abroad, or from public or private research centers.
L'archive ouverte pluridisciplinaire HAL, est destinée au dépôt et à la diffusion de documents scientifiques de niveau recherche, publiés ou non, émanant des établissements d'enseignement et de recherche français ou étrangers, des laboratoires publics ou privés. 


\title{
Polymerization of Cyclic Carbamates: A Practical Route to Aliphatic Pol- yurethanes
}

\author{
Dapeng Zhang, ' Yang Zhang, ${ }^{\dagger}$ Yujiao Fan, ${ }^{\dagger}$ Marie-Noelle Rager, ${ }^{\dagger}$ Vincent Guérineau," Laurent Bou- \\ teiller, Min-Hui Li, ${ }^{*}{ }^{\dagger}$ Christophe M. Thomas*, \\ ${ }^{\dagger}$ Chimie ParisTech, PSL University, CNRS, Institut de Recherche de Chimie Paris, UMR8247, 11 rue Pierre et Marie \\ Curie, 75231 Paris, France. \\ "Institut de Chimie des Substances Naturelles, CNRS UPR2301, Université Paris-Sud, Université Paris-Saclay, Avenue \\ de la Terrasse, 91198 Gif-sur-Yvette Cedex, France.
}

${ }^{\ddagger}$ Sorbonne Université, CNRS, Institut Parisien de Chimie Moléculaire, Equipe Chimie des Polymères, 4 Place Jussieu, 75005 Paris, France.

\begin{abstract}
A new polymerization system is reported that provides aliphatic polyurethanes with novel structures from the anionic ring-opening polymerization of 5-membered carbamates. By use of a bifunctional initiating system, the anionic ringopening polymerization of cyclic carbamates gives unimodal polymers with $Đ$ values generally narrow. A series of PUs with controlled molecular weights were synthesized by changing the reaction conditions. Detailed analysis of the reaction demonstrates that repeated acylations of in situ formed urethane anions, leads to the formation of the polyurethane.
\end{abstract}

\section{Introduction}

Due to their flexible structures and peculiar properties, polyurethanes (PUs) have been extensively exploited for a wide range of applications such as foams, high-performance coatings, adhesives. ${ }^{1}$ These versatile polymeric materials can exhibit thermoplastic, elastomeric and thermosetting behavior by tuning their chemical composition and morphological structure. ${ }^{3-5}$ Consequently, the worldwide production of these polymers increases each year and accounts for nearly $5 \mathrm{wt} \%$ of total worldwide polymer production. ${ }^{6}$ Inspired by the pioneering work of Bayer, ${ }^{2}$ several research groups have directed investigative efforts toward the synthesis of a variety of PUs. Generally, PUs are obtained by polyaddition of diols (or polyols) with diisocyanates (or polyisocyanates). This method requires drastic conditions to drive the reaction toward high conversion and uses toxic and highly moisture sensitive isocyanates, thus limiting their medical applications.

In this overall context, several isocyanate-free synthetic routes were developed to solve this problem..$^{7-9}$ The four most common approaches are (Figure 1): (1) polyaddition of cyclic dicarbonates and diamines (i.e., cyclic carbonate route); (2) polycondensation of linear activated dicarbonates and diamines (i.e., bis(dialkyl carbonate) route); (3) polycondensation of linear activated carbamates and diols (i.e., transurethanization route); (4) ring opening polymerization (ROP) of cyclic carbamates (i.e., ROP route). ${ }^{7,8}$ Among these methods, the cyclic carbonate route enables the production of poly(hydroxyurethane)s (PHU)s, which are more hydrophilic than conventional PUs and therefore can undergo higher water absorption. ${ }^{10}$ In addition, most cyclic carbonates are poorly reactive and necessitate harsh conditions. ${ }^{11,12}$ The second and third approaches make use of precursors or reagents that can be toxic. In addition, the reactions with diols usually require an efficient catalyst.

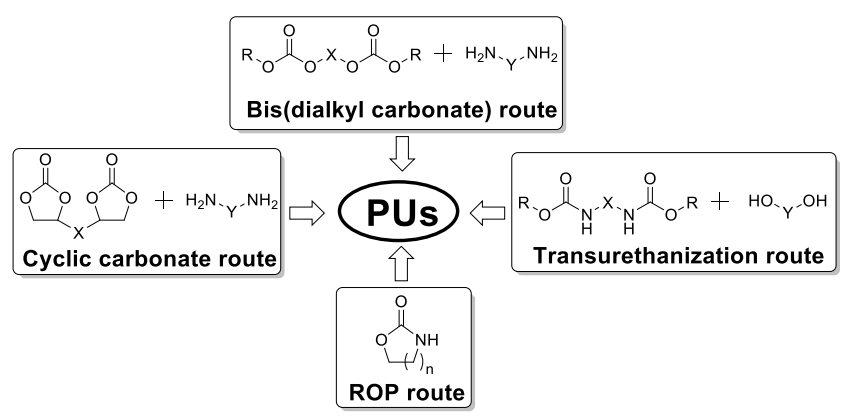

Figure 1. Main isocyanate-free routes to PUs.

Although ROP has important advantages over conventional syntheses (e.g., atom economy, waste reduction and energy consumption), it is much less developed due to the limited reactivity of the corresponding monomers (i.e., cyclic carbamates). To date, there is only few examples in the literature in which cationic initiators have been reported to prepare PUs. ${ }^{13-16}$ To develop an efficient synthesis of PUs, we propose that anionic systems capable of ROP of lactams might also exhibit interesting activity for the ROP of cyclic carbamates. Herein we report a new strategy, based on anionic ring-opening polymerization, to obtain aliphatic polyurethanes from cyclic carbamates. This anionic process provides practical access to polymers from 5-membered cyclic carbamates in high yields. 


\section{Results and Discussion}

We have initially synthesized the cyclic carbamate monomers a-d (Figure 2) and investigated the use of these monomers in the presence of different anionic initiators (e.g., sodium hydride, yttrium tris(isopropoxide)). In accordance with previous observations, ${ }^{17}$ we found them to be unreactive. By analogy with cyclic carbonates, we then hypothesized that cyclohexyl carbamate derivatives would have a better potential for ROP due to a more significant ring strain. Indeed, the five-membered ring of the aliphatic propylene carbonate is perfectly planar, ${ }^{18}$ while the ring on the fivemembered cyclohexyl carbonate is non-planar, in order to accommodate the conformational requirements of the alicyclic cyclohexyl ring.

To confirm the influence of the ring strain, a control experiment was therefore carried out with monomer $\mathbf{e}$ in the presence of $\mathrm{Y}(\mathrm{OiPr})_{3}$ (Figure 2). As expected, we were able to convert cyclohexyl carbamate e into PU but the molecular weights of the resulting polymers were relatively low (c.a. $1000 \mathrm{~g} / \mathrm{mol}$ ). In addition, the obtained PUs were insoluble in most common organic solvents. As already observed by Bayer, ${ }^{2}$ this low solubility is probably related to a high packing density of the polymer chains due to the density of hydrogen bonds between these chains. In order to facilitate the reorientation of the polymer chains, we chose to target our following efforts on monomer $\mathbf{f}$. In this case, the vinyl side-group of each cyclohexyl ring may prevent every urethane group to participate in a hydrogen bond. In addition, the introduction of functional groups is highly desirable in order to allow post-polymerization derivatization, ${ }^{19}$ that is often desired to modify physical properties, or chemical reactivity of a polymer. Satisfyingly, we observed the formation of PUs in the presence of $\mathrm{Y}(\mathrm{OiPr})_{3}$, even if the polymerization rate and control were low. As the obtained PUs displayed a good solubility in most organic solvents, we decided to focus on monomer $\mathbf{f}$ for the rest of the study.

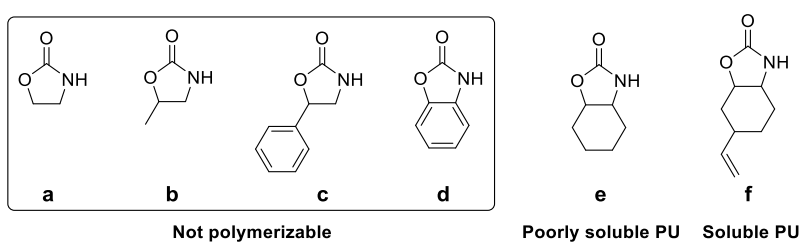

Figure 2. Cyclic carbamates prepared for ROP.

In order to develop a straightforward methodology to prepare monomer $\mathbf{f}$ on a large scale, we followed a three step procedure starting from commercially available 4-vinyl-1-cyclohexene-1,2-epoxide (1). Firstly, epoxide 1 underwent oxirane ring opening to give a mixture of regioisomers when reacted with an excess of ammonia in an $\mathrm{SN}_{2}-$ type reaction (isolated yield 98\%). ${ }^{20,21}$ Secondly, amino alcohols (2) and (3) reacted with ethyl chloroformate to yield the expected hydroxy urethanes (4) and (5) (isolated yield 92\%). Finally, regioisomers (6) and (7) produced by ringclosing reaction of $\mathbf{4}$ and $\mathbf{5}$ in the presence of excess sodium hydride were readily purified by silica gel chromatography (isolated yield 70\%). Assignment of structures to these regioisomers utilized NMR experiments $\left({ }^{1} \mathrm{H},{ }^{13} \mathrm{C}\right.$, COSY, NOESY, HSQC and HMBC) (Figures S1-S5). ${ }^{22}$ Although the reactivity of both cyclic carbamates was similar, we decided to focus on 7 (CHU) as it was obtained in a better yield.

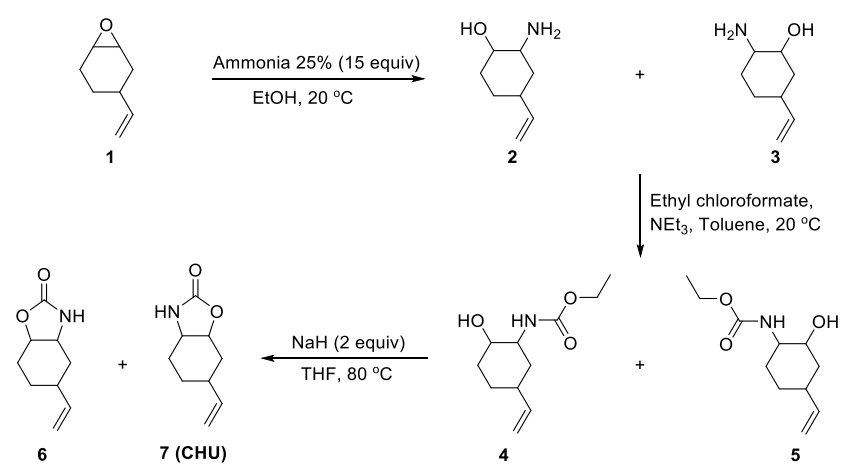

Figure 3. Synthetic route to 5-membered cyclic carbamate monomer with a vinyl group (CHU).

With an efficient synthesis of cyclic carbamates in hand, we were then interested in investigating the ring-opening polymerization of $\mathrm{CHU}$ using anionic initiators (Table 1). Taking into account prior developments in the anionic ROP of lactams, we set out to capitalize on these polymerization schemes to synthesize PUs with activated monomers. Firstly, the activation mechanism comprises the formation of an anionic monomer species. In this regard, strong bases capable of forming a free urethane anion may initiate an anionic polymerization. Then, the propagation consists in repeated acylations of the urethane anions, similarly to what was reported in the ROP of lactams. Therefore, the propagation rate of the polymerization reaction should be efficiently enhanced by the introduction or in situ generation of acyl derivatives (e.g., $N$-acylurethanes) which may act as growth centers. These acyl compounds are called co-initiators in this work (Figure 4).

We first evaluated the reactivity of a strong base (i.e., $n$ BuLi) in the presence of the co-initiator I1 (Table 1, Entry 1). The resulting initiating system was able to convert $\mathrm{CHU}$ into PU and showed monomodal distribution with experimental number-average molecular weights $\left(M_{\mathrm{n}}\right.$, calculated by NMR) close to the theoretical ones. In addition, the distribution observed by SEC was much narrower than the ones described in the literature. ${ }^{16}$ These data indicate that the polymerization proceeded in a controlled fashion (i.e., without any significant side reactions), as confirmed by MALDI-TOF mass spectrometry (vide infra). As a control experiment, the reactivity of $n$-BuLi in the absence of co-initiator was then investigated and we observed that only oligomers were formed (Table 1, Entry 2). Polymerizations were also performed either with lithium bis(trimethylsilyl)amide (Table 1, Entry 3) or sodium hydride (Table 1, Entry 4) in the presence of I1. These systems were less efficient and the resultant polymers revealed broader molecular-weight distributions. Also, we performed a polymerization reaction using a clean combination of 1 equiv benzoyl chloride (I2) with 2 equiv of $n$-BuLi in order to in situ generate the coinitiator I1 (Table 1, Entry 5). 


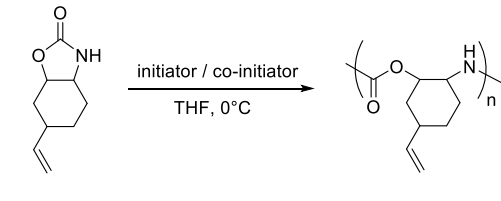

$\mathrm{CHU}$

PU

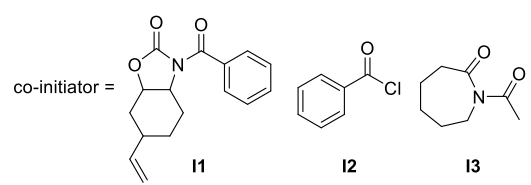

Figure 4. Ring-opening polymerization of CHU promoted by different initiator/co-initiator systems.

These results showed that benzoyl chloride was less efficient than I1. Indeed, we observed that $n$-BuLi/I2 system reacted more slowly and produced polymers with lower molecular weights. As commercially available $N$-acetylcaprolactam was already used for the anionic ROP of $\varepsilon$-caprolactam, it was interesting to observe that it was also active in the presence of $n$-BuLi (Table 1, Entry 6) but less efficient than I1 (Table 1, Entry 1). Several reactions were performed by changing the monomer-to-initiator ratio and we found that $n$-BuLi/I1 polymerized up to 50 equiv of CHU (Table 1, Entry 9). We observed that the addition of $\mathrm{LiBr}$ was required in order to obtain a conversion higher than 50\% (Table 1, Entry 9). We assume that the longer chains restrict the solubility of PU and therefore its reactivity. In this regard, Li salts are known to effectively break the intermolecular hydrogen bonds of polymers.

The synthesized PUs were characterized by infrared spectroscopy, TGA and DSC (Figures S15-S17). On the basis of prior IR assignments of classical polyurethanes, ${ }^{23}$ our CHU-derived PUs featured two strong characteristic peaks which can be attributed to carbonyl groups and secondary amines (Figure S15). TGA analysis confirmed that the aliphatic PUs are stable below $200{ }^{\circ} \mathrm{C}$ (Figure S16). DSC measurements of a selected PU sample (Table 1, entry 1) showed the presence of a high glass transition temperature $\left(T_{\mathrm{g}}\right)$ at $150{ }^{\circ} \mathrm{C}$ (Figure S17). Finally, we were also able to prepare an amphiphilic PU- $g$-PEG graft copolymer by the radicalmediated thiol-ene functionalization of a linear PU homopolymer backbone and a $\mathrm{mPEG}_{12}-\mathrm{SH}$ (Figures S20-S24).

Table 1. AROP of CHU monomer to prepare PUs.

\begin{tabular}{|c|c|c|c|c|c|c|c|c|c|c|}
\hline Entrya & Initiator & Co-initiator & $\begin{array}{l}\text { Monomer/Initia- } \\
\text { tor/Co-initiator }\end{array}$ & $\begin{array}{l}\text { Time } \\
\text { (h) }\end{array}$ & $\begin{array}{l}\text { Conv. } \\
(\%)^{b}\end{array}$ & $\begin{array}{c}M_{\mathrm{n}, \text { theo }} \\
(\mathrm{g} / \mathrm{mol})\end{array}$ & $\begin{array}{c}M_{\mathrm{n}, \mathrm{NMR}} \\
(\mathrm{g} / \mathrm{mol})^{\mathrm{b}}\end{array}$ & $\mathrm{DPb}$ & $\begin{array}{c}M_{\mathrm{n}, \mathrm{SEC}} \\
(\mathrm{g} / \mathrm{mol})^{\mathrm{c}}\end{array}$ & PDIc \\
\hline 1 & $n$-BuLi & I1 & $20 / 1 / 1$ & 5 & $91 \%$ & 3300 & 3900 & 23 & 5400 & 1.23 \\
\hline 2 & $n-\mathrm{BuLi}$ & - & $20 / 1 / 1$ & 5 & $8 \%$ & 540 & ND & ND & ND & ND \\
\hline 3 & $\operatorname{LiN}(\mathrm{TMS})_{2}$ & I1 & $20 / 1 / 1$ & 5 & $84 \%$ & 2900 & 4600 & 27 & 4400 & 1.55 \\
\hline 4 & $\mathrm{NaH}$ & I1 & $20 / 1 / 1$ & 5 & $47 \%$ & 1800 & 3600 & 21 & 2100 & 1.50 \\
\hline 5 & $n-\mathrm{BuLi}$ & I2 & $20 / 2 / 1$ & 5 & $73 \%$ & 2600 & 2300 & 12 & 2800 & 1.33 \\
\hline 6 & $n$-BuLi & I3 & $20 / 1 / 1$ & 5 & $79 \%$ & 2800 & ND & ND & 5300 & 1.22 \\
\hline 7 & $n-\mathrm{BuLi}$ & I1 & $10 / 1 / 1$ & 4 & $83 \%$ & 1700 & 2400 & 14 & 3200 & 1.29 \\
\hline 8 & $n$-BuLi & I1 & $30 / 1 / 1$ & 6 & $81 \%$ & 4300 & 4400 & 26 & 6100 & 1.28 \\
\hline $9 d$ & $n$-BuLi & I1 & $50 / 1 / 1$ & 24 & $81 \%$ & 7100 & 7800 & 46 & 7500 & 1.32 \\
\hline
\end{tabular}

a The concentration of co-initiators were all $0.0188 \mathrm{M}$; b Conversion of monomers, degree of polymerization (DP) and $M_{\mathrm{n}, \mathrm{NMR}}$ were calculated by ${ }^{1} \mathrm{H}$ NMR; ${ }^{c} M_{\mathrm{n}, \mathrm{NMR}}$ and PDI were obtained by SEC with THF as eluent and PS as calibration; ${ }^{\mathrm{d}} \mathrm{LiBr}(1 \mathrm{wt} \%)$ was added in the polymerization solution.
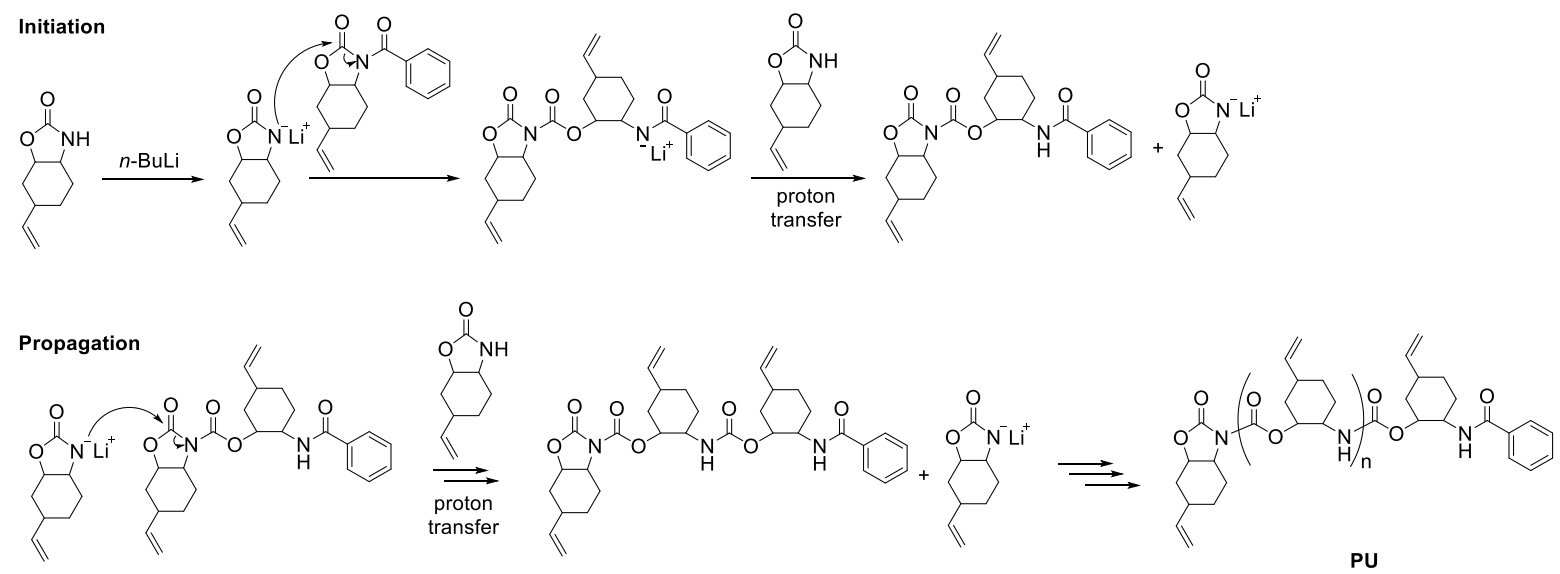

Figure 5. Mechanism of anionic ROP of CHU with I1 as the co-initiator. 
Mechanistic studies. The preactivation pathway depicted in Figure 5 explains the observed reactivity for the $n$ $\mathrm{BuLi} / \mathbf{I 1}$ system. The initiation process involves an intermolecular transurethanization (i.e., disproportionation) between the co-initiator $\mathbf{I}$ and the urethane anion. ${ }^{24}$ Acylation of the urethane nitrogen increases the electron deficiency of the urethane linkage, and this increases the reactivity of the ring urethane carbonyl toward nucleophilic attack by the urethane anion. The obtained amido anion is immediately neutralized by a monomer proton to regenerate the urethane anion (or polymer urethane anion) and to form an amidoacylurethane derivative. Evidence of this initiation mechanism was confirmed by MALDI-TOF mass spectrometry analysis that consistently showed a distribution of peaks corresponding to polymer chains terminated by the expected end-groups (Figure 6). Finally, the resulting $\mathrm{N}$-acylated terminal urethane center can react with a monomer anion to give a new anionic oligomeric species. The propagation consists in successive reactions of monomer anions and $N$-acylated center at the polymer chain end.

In order to verify the mechanistic pathway, online ATR-IR spectroscopy was used to study the formation of PU with the $n$-BuLi/I1 system. Rates of polymerization of CHU at $0{ }^{\circ} \mathrm{C}$ in THF solution were monitored by in situ IR spectroscopy using a ReactIR instrument fitted with an immersible diamond probe. The reaction progress was monitored every minute for $16 \mathrm{~h}$. We first monitored a 1/1/1 (monomer, initiator, co-initiator) reaction. A representative stack plot showing the change in IR spectra with CHU conversion is shown in Figure 7. The rate of formation of a new urethane species $\left(1723 \mathrm{~cm}^{-1}, 1642 \mathrm{~cm}^{-1}\right)$ rapidly increases during the first $2 \mathrm{~min}$. This fits well with the concentration of $\mathrm{CHU}$ (1776 $\mathrm{cm}^{-1}, \mathrm{C}=0$ group 1), which decreases over the same time until it is fully consumed (Figure S18). We also observed that the $\mathrm{C}=0$ groups $\mathbf{2}$ and $\mathbf{3}\left(1798 \mathrm{~cm}^{-1}\right.$ and 1690 $\mathrm{cm}^{-1}$ respectively) from the co-initiator disappeared completely after $16 \mathrm{~h}$ (Figures $7 \mathrm{~b}, \mathrm{c}$ ). In addition, by comparing the spectra of monomer, co-initiator and the crude product after in situ IR experiment (Figure 7c), we clearly observed the disappearance of co-initiator signals in the crude product and appearance of signals attributed to the PU oligomers. By comparing the ${ }^{13} \mathrm{C}$ NMR spectra of monomer, co-initiator and the crude product, we could see the appearance of new carbonyl signals (Figure S14) attributed to the PU oligomers.

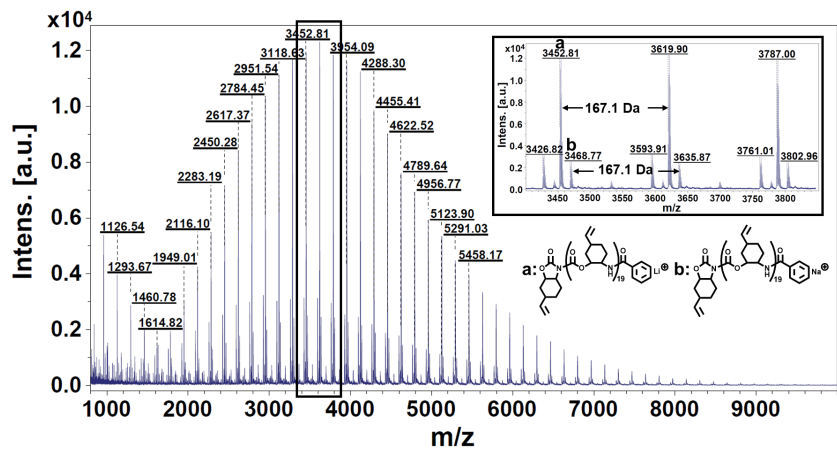

Figure 6. MALDI-TOF mass spectrometry of PU (Table 1, Entry 1). The molecular weight of the repeating unit corresponds to $167.1 \mathrm{Da}$.
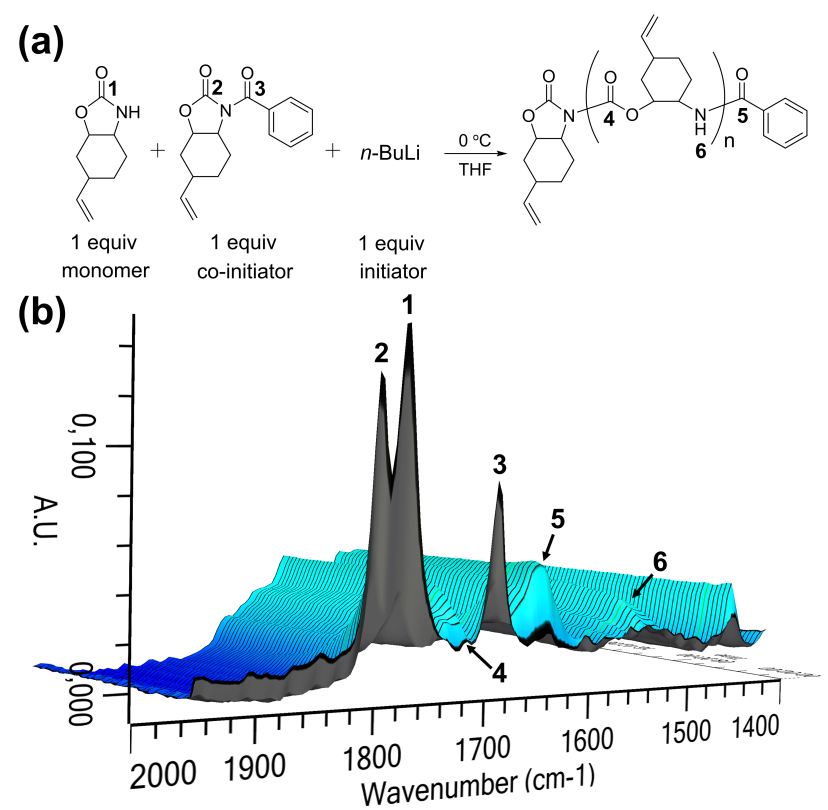

(c)

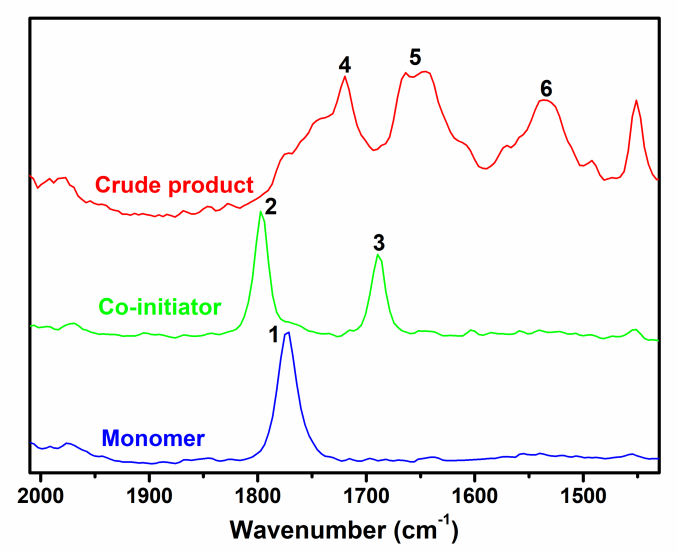

Figure 7. In situ IR experiments of the anionic ROP mechanism. (a) Model reaction equation with the molar ratio of monomer, initiator and co-initiator being $1 / 1 / 1$. (b) In situ IR spectra of the reaction mixture from 0-16 h. (c) IR spectra of monomer, co-initiator and the crude product.

Using the ATR-IR method, we studied the variation of the monomer concentration during the polymerization process. As already reported, ${ }^{25}$ the absorbance intensity of the characteristic peaks in IR spectrum is closely related to the concentrations of both reagents and products. ${ }^{26,27}$ Therefore, we were able to obtain the real-time concentration values by knowing the real-time absorbance intensities of the carbonyl group attributed to $\mathrm{CHU}\left(1776 \mathrm{~cm}^{-1}\right.$ in the in situ IR spectra) and the initial monomer concentration. To this end, we carried out one polymerization experiment with the molar ratio of monomer, initiator and co-initiator being 30/1/1 monitored by in situ IR (Figure S19). For this polymerization, we found that the monomer concentration decreased linearly with time (i.e., first-order kinetics). In addition, we were able to determine that the apparent ROP rate constant ( $k_{\text {app}}$ ) of this $30 / 1 / 1$ reaction was $3.5 \cdot 10^{-3} \mathrm{~min}^{-1}$ (Figure S19b). 


\section{Conclusions}

The ROP described here enables direct access to polyurethanes in mild conditions. This new method is operationally facile and provides a distinct advance towards the development of an atom-economical approach for isocyanate-free synthesis of PUs. A series of PUs with different molecular weights were synthesized by changing the reaction conditions. We have shown, with the help of mechanistic studies that the origin of the polymerization activity of our system in carbamate ROP is very likely to be caused by the formation of highly active anionic species. Efforts directed at the study of the physical properties of these new aliphatic PUs are ongoing in our laboratories.

\section{ASSOCIATED CONTENT}

Supporting Information. Details of synthesis, polymerization and characterization, and supporting figures. This material is available free of charge via the Internet at http://pubs.acs.org.

\section{AUTHOR INFORMATION}

\section{Corresponding Author}

* christophe.thomas@chimie-paristech.fr

*min-hui.li@chimie-paristech.fr

Notes

The authors declare no competing financial interest.

\section{ACKNOWLEDGMENT}

We acknowledge financial support from ENSCP, CNRS and the French National Research Agency (ANR-16-CE29-0028). Y. Z. thanks the LabEx MiChem, part of French state funds managed by the ANR within the Investissements d'Avenir programme under reference ANR-11-IDEX-0004-02, for support. D. Z. gratefully acknowledges financial support from China Scholarship Council for funding his $\mathrm{PhD}$ scholarship. We thank Guylaine Ducouret and Mohamed Hanafi for their help in TGA analysis. C.M.T. is grateful to the Institut Universitaire de France.

\section{REFERENCES}

(1) Chattopadhyay, D. K.; Raju, K. V. S. N. Structural engineering of polyurethane coatings for high performance applications. Prog. Polym. Sci. 2007, 32, 352-418.

(2) Bayer, O. Das Di-Isocyanat-Polyadditionsverfahren (Polyurethane). Angew. Chem. 1947, 59, 257-272.

(3) Delebecq, E.; Pascault, J.-P.; Boutevin, B.; Ganachaud, F. On the versatility of urethane/urea bonds: reversibility, blocked isocyanate, and non-isocyanate polyurethane. Chem. Rev. 2013, 113, 80118.

(4) Engels, H.-W.; Pirkl, H.-G.; Albers, R.; Albach, R. W.; Krause, J.; Hoffmann, A.; Casselmann, H.; Dormish, J. Polyurethanes: versatile materials and sustainable problem solvers for today's challenges. Angew. Chem. Int. Ed. 2013, 52, 9422-9441.

(5) Krol, P. Synthesis methods, chemical structures and phase structures of linear polyurethanes. Properties and applications of linear polyurethanes in polyurethane elastomers, copolymers and ionomers. Prog. Mater Sci. 2007, 52, 915-1015.

(6) Sardon, H.; Engler, A. C.; Chan, J. M. W.; Garcia, J. M.; Coady, D. J.; Pascual, A.; Mecerreyes, D.; Jones, G. O.; Rice, J. E.; Horn, H. W.; Hedrick, J. L. Organic acid-catalyzed polyurethane formation via a dual-activated mechanism: unexpected preference of $\mathrm{N}$-activation over 0-activation of isocyanates. J. Am. Chem. Soc. 2013, 135, 16235-16241.

(7) Sardon, H.; Pascual, A.; Mecerreyes, D.; Taton, D.; Cramail, H.; Hedrick, J. L. Synthesis of polyurethanes using organocatalysis: a perspective. Macromolecules 2015, 48, 3153-3165.

(8) Maisonneuve, L.; Lamarzelle, O.; Rix, E.; Grau, E.; Cramail, H. Isocyanate-free routes to polyurethanes and poly(hydroxy urethane)s. Chem. Rev. 2015, 115, 12407-12439.

(9) Schmidt, S.; Ritter, B. S.; Kratzert, D.; Bruchmann, B.; Muelhaupt, R. Isocyanate-free route to poly(carbohydrate-urethane) thermosets and $100 \%$ bio-based coatings derived from glycerol feedstock. Macromolecules 2016, 49, 7268-7276.

(10) Tomita, H.; Sanda, F.; Endo, T. Structural analysis of polyhydroxyurethane obtained by polyaddition of bifunctional five-membered cyclic carbonate and diamine based on the model reaction. $J$. Polym. Sci., Part A: Polym. Chem. 2001, 39, 860-867.

(11) Blain, M.; Jean-Gerard, L.; Auvergne, R.; Benazet, D.; Caillol, S.; Andrioletti, B. Rational investigations in the ring opening of cyclic carbonates by amines. Green Chem. 2014, 16, 4286-4291.

(12) Lamarzelle, O.; Durand, P.-L.; Wirotius, A.-L.; Chollet, G.; Grau, E.; Cramail, H. Activated lipidic cyclic carbonates for non-isocyanate polyurethane synthesis. Polym. Chem. 2016, 7, 1439-1451.

(13) Neffgen, S.; Keul, H.; Höcker, H. Ring-opening polymerization of cyclic urethanes and ring-closing depolymerization of the respective polyurethanes. Macromol. Rapid Commun. 1996, 17, 373382.

(14) Neffgen, S.; Kusan, J.; Fey, T.; Keul, H.; Höcker, H. Synthesis and thermal properties of [n]-polyurethanes. Macromol. Chem. Phys. 2000, 201, 2108-2114.

(15) Neffgen, S.; Keul, H.; Höcker, H. Poly(tetrahydrofuran)-blockpoly(trimethylene urethane): synthesis and characterization. Macromol. Rapid Commun. 1999, 20, 194-199.

(16) Kusan, J.; Keul, H.; Höcker, H. Cationic ring-opening polymerization of tetramethylene urethane. Macromolecules 2001, 34, 389395.

(17) For instance, the ring-opening polymerization of dimethylene urethane is a thermodynamically unfavored process: Lebedev, B.; Veridusova, V.; Höcker, H.; Keul, H. Thermodynamics of aliphatic cyclic urethanes, of their ring-opening polymerization, and of corresponding polyurethanes. Macromol. Chem. Phys. 2002, 203, 1114-1125.

(18) Darensbourg, D. J.; Holtcamp, M. W.; Struck, G. E.; Zimmer, M. S.; Niezgoda, S. A.; Rainey, P.; Robertson, J. B.; Draper, J. D.; Reibenspies, J. H. Catalytic activity of a series of Zn(II) phenoxides for the copolymerization of epoxides and carbon dioxide. J. Am. Chem. Soc. 1999, 121, 107-116.

(19) Fournier, L.; Robert, C.; Pourchet, S.; Gonzalez, A.; Williams, L.; Prunet, J.; Thomas, C. M. Facile and efficient chemical functionalization of aliphatic polyesters by cross metathesis. Polym. Chem. 2016, 7, 3700-3704.

(20) McManus, S. P.; Larson, C. A.; Hearn, R. A. The synthesis of aminoalcohols from epoxides and ammonia. Synth. Commun. 1973, 3 , 177-180.

(21) Hawkins, L. R.; Bannard, R. A. B. Ammonolysis of 1,2-epoxycyclohexane and trans-2-bromocyclohexanol. Can. J. Chem. 1958, 36, 220-227.

(22) As CHU has three stereogenic centers, it is obtained as a mixture of four stereoisomers (two pairs of diastereomers) (Figure S8) with a molar ratio of about 6:4 (Figure S11). The detailed stereochemistry analysis of $\mathrm{CHU}$ is summarized in the supporting information.

(23) Chiono, V.; Mozetic, P.; Boffito, M.; Sartori, S.; Gioffredi, E.; Silvestri, A.; Rainer, A.; Giannitelli, S. M.; Trombetta, M.; Nurzynska, D.; Di Meglio, F.; Castaldo, C.; Miraglia, R.; Montagnani, S.; Ciardelli, G. Polyurethane-based scaffolds for myocardial tissue engineering. Interface Focus 2014, 4: 20130045.

(24) Evans, D. A.; Britton, T. C.; Ellman, J. A. Contrasteric carboximide hydrolysis with lithium hydroperoxide. Tetrahedron Letters 1987, 28, 6141-6144. 
(25) Deng, H.; Shen, Z.; Li, L.; Yin, H.; Chen, J. Real-time monitoring of ring-opening polymerization of tetrahydrofuran via in situ Fourier transform infrared spectroscopy. J. Appl. Polym. Sci. 2014, 131, 40503.

(26) Messman, J. M.; Storey, R. F. Real-time monitoring of the ringopening polymerization of rac-lactide with in situ attenuated total reflectance/Fourier transform infrared spectroscopy with conduit and diamond-composite sensor technology. J. Polym. Sci., Part A: Polym. Chem. 2004, 42, 6238-6247.

(27) Schwartz, T. J.; Lyman, S. D.; Motagamwala, A. H.; Mellmer, M. A.; Dumesic, J. A. Selective hydrogenation of unsaturated carboncarbon bonds in aromatic-containing platform molecules. ACS Catal. 2016, 6, 2047-2054. 


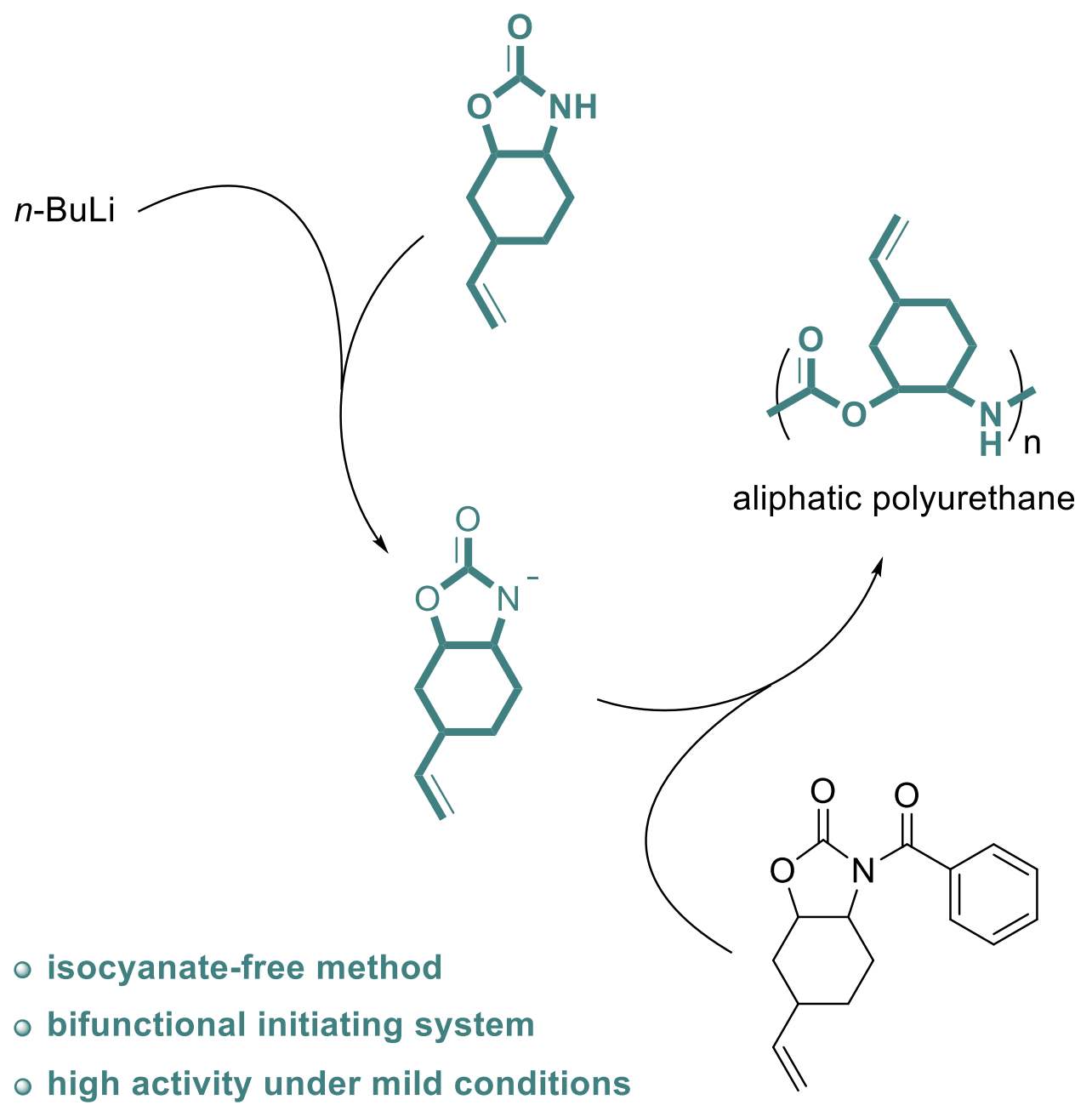

